\title{
Machinability of cast titanium alloy Ti-6Al-4V with addition of boron
}

\author{
Stefan Cedergren ${ }^{\mathrm{a}^{*}}$, Robert Pederson ${ }^{\mathrm{b}}$

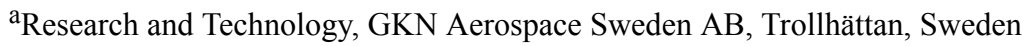 \\ ${ }^{\mathrm{b}}$ Department of Engineering Science, Division of Subtractive and Additive Manufacturing, University West, Trollhättan, Sweden \\ *stefan.cedergren@gknaerospace.com
}

\begin{abstract}
$\underline{\text { Abstract }}$
Cast titanium products generally have coarser microstructures compared to wrought, which explains their limited mechanical properties. However, instead of additional thermo-mechanical processing steps, as in the case of wrought components, the microstructure of castings can be refined by additions of boron. This enhances yield strength, tensile strength and ductility. In order to investigate the influence on machining of this microstructural refinement, cutting tests were performed in three different Ti-6Al-4V castings, having $0,0.06$ and 0.11 wt.\% boron. Five machinability criteria were studied; cutting force, chip breakability, burr formation, surface roughness and tool wear. The results show anisotropic deformation behavior in chips when alpha colony size is on the same order of magnitude as the primary deformation zone, or larger. There was little or no influence on cutting forces and burr formation, however chip breakability and tool life was reduced when boron was added. Surface roughness showed a more complex behavior where $0.06 \mathrm{wt}$ \% boron resulted in rougher surfaces compared to the other compositions at low feed rate.
\end{abstract}

\section{$\underline{\text { Introduction }}$}

For highly stressed components wrought material is often used because of its strength advantage over cast material, where the increased strength comes from the microstructure refinement obtained during the thermo-mechanical processing. These additional process steps for wrought material increase cost, and it would therefore be advantageous to refine the cast microstructure directly by other means. One possible way is to add boron, which has been shown to refine microstructure giving the benefit of increased strength in cast alloys without adding any additional processing steps [1]. However, manufacturing cost of parts is also affected by subsequent machining operations, it is therefore important to take the impact on machinability of these boron additions into account when total cost of manufactured parts is analyzed.

When it comes to machinability, titanium alloys are known as difficult-to-cut materials, because of their: (i) low thermal conductivity, resulting in high temperatures in the tool-chip interface combined with a high chemical reactivity resulting in a tendency for the chip to weld to the tool, leading to poor tool life; (ii) Modulus of elasticity is low when compared to steel, but cutting forces are on a comparable level, which means that both static deflections and dynamic, i.e. vibrations, are a key issue. They are also known to produce shear-localized chips, further aggravating problems with vibrations. However, at low speeds, continuous chips are produced, while an increase in either cutting speed or feed rate, favors the transition to shear-localized chips [2].

Investigations on the influence of different heat treatments in wrought Ti-6Al-4V on machinability has been studied earlier [3]. Both cutting forces and tool wear were higher when machining a coarse beta annealed microstructure, compared to machining of finer microstructures in the as-forged, mill-annealed and duplex annealed conditions. The hypothesis was that a rough laminar microstructure results in higher shear stresses. It has also been demonstrated that a coarse microstructure, i.e. when the size of microstructural features were on the same order of magnitude as the primary cutting zone, resulted in anisotropic chip formation [4]. The actual deformation was found to depend on the orientation of the beta lamellae; however there was no influence on cutting forces when compared with two other microstructures; bi-modal and equiaxed. This influence of beta lamellae orientation was also found by Wagner et al. when turning Ti-6Al-4V having two different microstructures, where it was stressed that new material behavior laws are needed to describe the material inhomogeneity [5].

The control of microstructure through addition of boron in Ti-6Al-4V, with its influence on chip formation has also been shown to influence vibrations [6]. However, the term machinability is unambiguous, and there exists many definitions [7]. In the present paper the influence of boron on machinability in terms of chip formation, cutting forces, burr formation, chip breakability, surface roughness and tool wear is investigated.

\section{Experimental}

\section{Work material}

(C) The Authors, published by EDP Sciences. This is an open access article distributed under the terms of the Creative Commons Attribution License 4.0 (http://creativecommons.org/licenses/by/4.0/). 
Induction skull melted ingots with three different chemical compositions were used during the experiments, see Table 1. More information about the investigated materials can be found in [8].

Table 1. Chemical compositions of the investigated materials [8].

\begin{tabular}{|l|l|l|l|l|l|l|l|l|l|l|}
\hline Alloy & $\mathrm{Al}$ & $\mathrm{V}$ & $\mathrm{B}$ & $\mathrm{O}$ & $\mathrm{Fe}$ & $\mathrm{C}$ & $\mathrm{N}$ & $\mathrm{H}$ & $\mathrm{Y}$ & $\mathrm{Ti}$ \\
\hline Ti-64 & 6.16 & 4.04 & $<0.001$ & 0.20 & 0.20 & 0.010 & 0.002 & $<0.001$ & $<0.001$ & Bal. \\
\hline Ti-64-0.06B & 6.24 & 4.06 & 0.06 & 0.19 & 0.18 & 0.012 & 0.003 & $<0.001$ & $<0.001$ & Bal. \\
\hline Ti-64-0.11B & 6.18 & 4.02 & 0.11 & 0.24 & 0.19 & 0.007 & 0.004 & $<0.001$ & $<0.001$ & Bal. \\
\hline
\end{tabular}

The additions of boron resulted in refinement of microstructure as evidenced by the smaller alpha colony sizes, see Table 2 . Micrographs of the resulting microstructures can be found in Figure 1.

Table 2. Microstructural features of the investigated materials [8].

\begin{tabular}{|l|c|c|c|}
\hline Microstructural feature & Ti-64 & Ti-64-0.06B & Ti-64-0.11B \\
\hline Volume fraction of $\beta$ phase, $\%$ & $17.1 \pm 3.8$ & $14.2 \pm 2.8$ & $13.2 \pm 2.8$ \\
\hline Volume fraction of $\alpha$ phase, $\%$ & $82.9 \pm 3.8$ & $85.5 \pm 2.8$ & $86.3 \pm 2.8$ \\
\hline Volume fraction of TiB phase, $\%$ & 0 & $0.3 \pm 0.2$ & $0.6 \pm 0.3$ \\
\hline Thickness of $\alpha$ lath, $\mu \mathrm{m}$ & $2.7 \pm 1.11$ & $4.02 \pm 1.25$ & $3.90 \pm 1.25$ \\
\hline Length of $\alpha$ lath, $\mu \mathrm{m} / \mu \mathrm{m}^{3}$ & $0.12 \pm 0.05$ & $0.05 \pm 0.02$ & $0.09 \pm 0.02$ \\
\hline$\alpha$ colony size, $\mu \mathrm{m}$ & $250.4 \pm 150.2$ & $53.4 \pm 3.0$ & $23.4 \pm 3.0$ \\
\hline Thickness of grain boundary & $4.7 \pm 1.5$ & $6.8 \pm 2.2$ & $7.0 \pm 2.2$ \\
\hline
\end{tabular}

$<0.001 w t \% B$

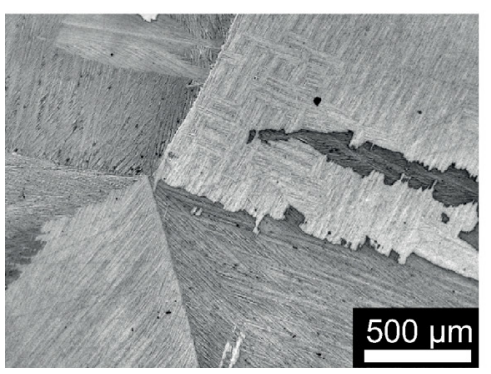

$0.06 w t \% B$

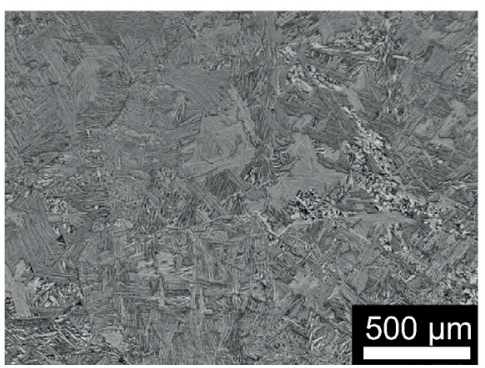

$0.11 \mathrm{wt} \% \mathrm{~B}$

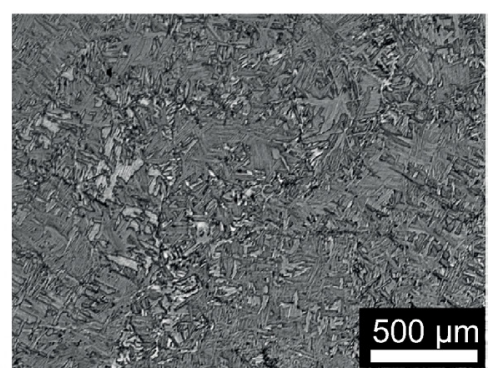

Figure 1. Micrographs of the three microstructures investigated.

The increase of hardness associated with the refinement of microstructure can be found in Table 3 .

Table 3. Hardness of the investigated materials [8].

\begin{tabular}{|l|l|l|}
\hline Alloy & Micro hardness (HV) & Macro hardness (HV) \\
\hline Ti-64 & $323 \pm 33$ & $323 \pm 32$ \\
\hline Ti-64-0.06B & $335 \pm 20$ & $350 \pm 19$ \\
\hline Ti-64-0.11B & $337 \pm 25$ & $353 \pm 21$ \\
\hline
\end{tabular}


The same tungsten carbide supplier and grade was used throughout the experiments, Sandvik Coromant H13A. Tool holder rake angle was 0 degree and entering angle was 91 degree for all experiments. A summary of cutting parameters, tools, coolant and machine tool used during experiments can be found in Table 4.

Table 4. Experimental data.

\begin{tabular}{|l|l|l|l|l|l|}
\hline & $\begin{array}{l}\text { Chip formation \& } \\
\text { Cutting forces }\end{array}$ & Burr formation & Chip breakability & Surface roughness & Tool wear \\
\hline Insert geometry & TCMW16T304 & TCMW16T304 & TCMT 16 T3 04-KF & TCMW16T304 & $\begin{array}{l}\text { TCMT 16 T3 } \\
04-K F\end{array}$ \\
\hline $\begin{array}{l}\text { Cutting speed } \\
{[\mathrm{m} / \mathrm{min}]}\end{array}$ & 50 & 50 & 50 & 50 & 120 \\
\hline $\begin{array}{l}\text { Feed rate } \\
{[\mathrm{mm} / \text { revolution }]}\end{array}$ & $\begin{array}{l}0.05,0.10,0.15, \\
0.20,0.25\end{array}$ & $0.05,0.10,0.15$ & $0.06,0.11,0.16$ & $0.05,0.10,0.20$ & 0.06 \\
\hline Depth of cut $[\mathrm{mm}]$ & 2.6 & 0.5 & $0.25,0.50$ & 0.5 & 0.5 \\
\hline Coolant & Cimperial 821, 7\% & Hysol XF, 7\% & Cimperial 821, 7\% & Hysol XF, 7\% & Hysol XF, 7\% \\
\hline Machine & Storebro STM2000 & Emco 365 & Storebro STM2000 & Emco 365 & Emco 365 \\
\hline $\begin{array}{l}\text { Dynamometer } \\
\text { Kistler Type }\end{array}$ & \multicolumn{1}{|l}{-} & & & $\begin{array}{l}\text { Kistler Type } \\
9257 \mathrm{~A}\end{array}$ \\
\hline
\end{tabular}

\section{Chip formation and cutting forces}

Near orthogonal machining was done by axial cutting of $2.6 \mathrm{~mm}$ thick flanges.

\section{Burr formation}

These tests were performed during face turning, where machining was interrupted after a minimum of twenty revolutions.

\section{Chip breakability}

Chips were collected after longitudinal machining experiments.

\section{Surface roughness}

Face turning experiments were conducted, with a fresh tool used for all materials, to avoid influence of tool wear. Three surface roughness measurements were performed for each cutting condition and material, using a Surfascan Somicronic with a stylus radius of $2 \mu \mathrm{m}$. Stylus radius and filters were chosen according to ISO 4288:1998. Three-dimensional surface scans were also investigated using a Taylor Hobson Talysurf CCI MP HS.

\section{Tool wear}

High cutting speed and lowest recommended feed rate for the tool geometry was chosen, in order to maximize the spiral cutting length and tool wear rate. The experiments were conducted under face turning conditions with an outer diameter of $73.5 \mathrm{~mm}$ and inner diameter of $20 \mathrm{~mm}$. Figure 2 shows how flank wear was measured.

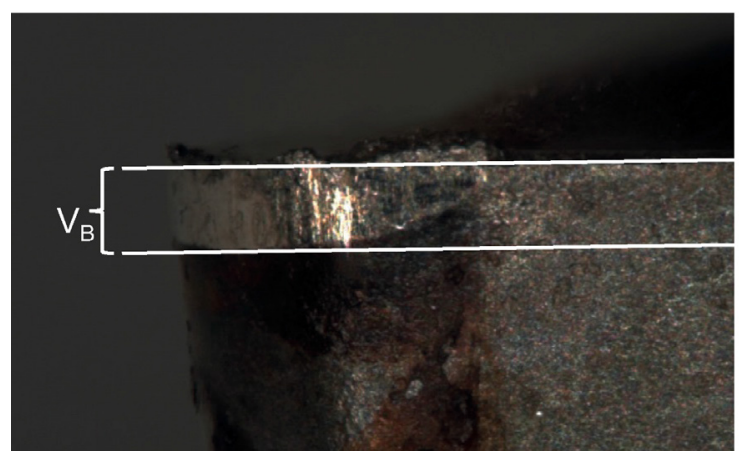

Figure 2. Measurement of flank wear $\left(\mathrm{V}_{\mathrm{B}}\right)$. 


\section{$\underline{\text { Results and discussion }}$}

\section{Chip morphology}

The results show that homogeneity of deformation increases with increased boron content, and that the transition in chip morphology from continuous to shear-localized is clearer, see Figure 3. In the coarsest microstructure, with no boron, there is a mixture of shear localized and continuously deformed chip at all feed rates.

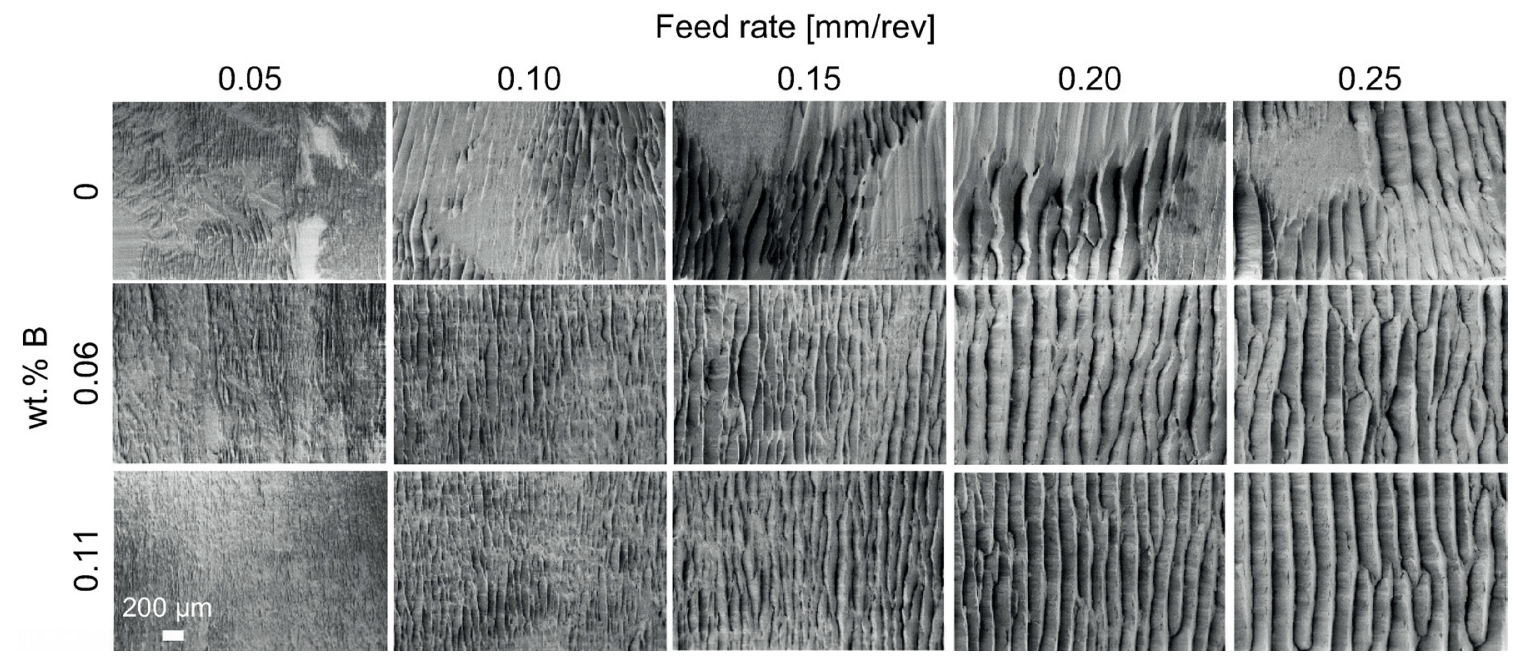

Figure 3. Free side of chips machined with a cutting speed of $50 \mathrm{~m} / \mathrm{min}$, showing the increasing isotropic behavior with increase of boron. Magnification is the same for all images.

Cross sections of chips were also investigated, shown in Figure 4, where variation in homogeneity of deformation also can be seen between the three materials. For the 0.06 and $0.11 \mathrm{wt}$ \% $\%$ boron microstructures, regions of severe shear-localization even at the lower feed rates are found. This anisotropic shear localization in coarse microstructure is in good agreement with previous results in wrought Ti-6Al-4V [4], where the same behavior was found in material with large alpha colonies. The cast material with the finest microstructure, i.e. $0.11 \mathrm{wt} . \%$ boron, show chip formation behavior very close to the fine wrought microstructures, i.e. gradual transition from a more continuous type of chip to severely shear-localized as feed rate is increased. 


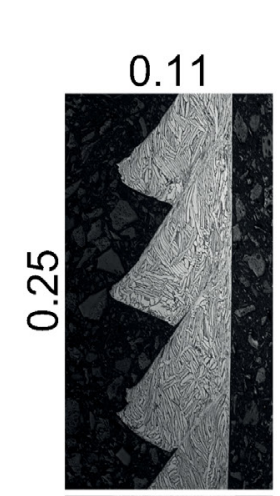

$$
w t \% B
$$
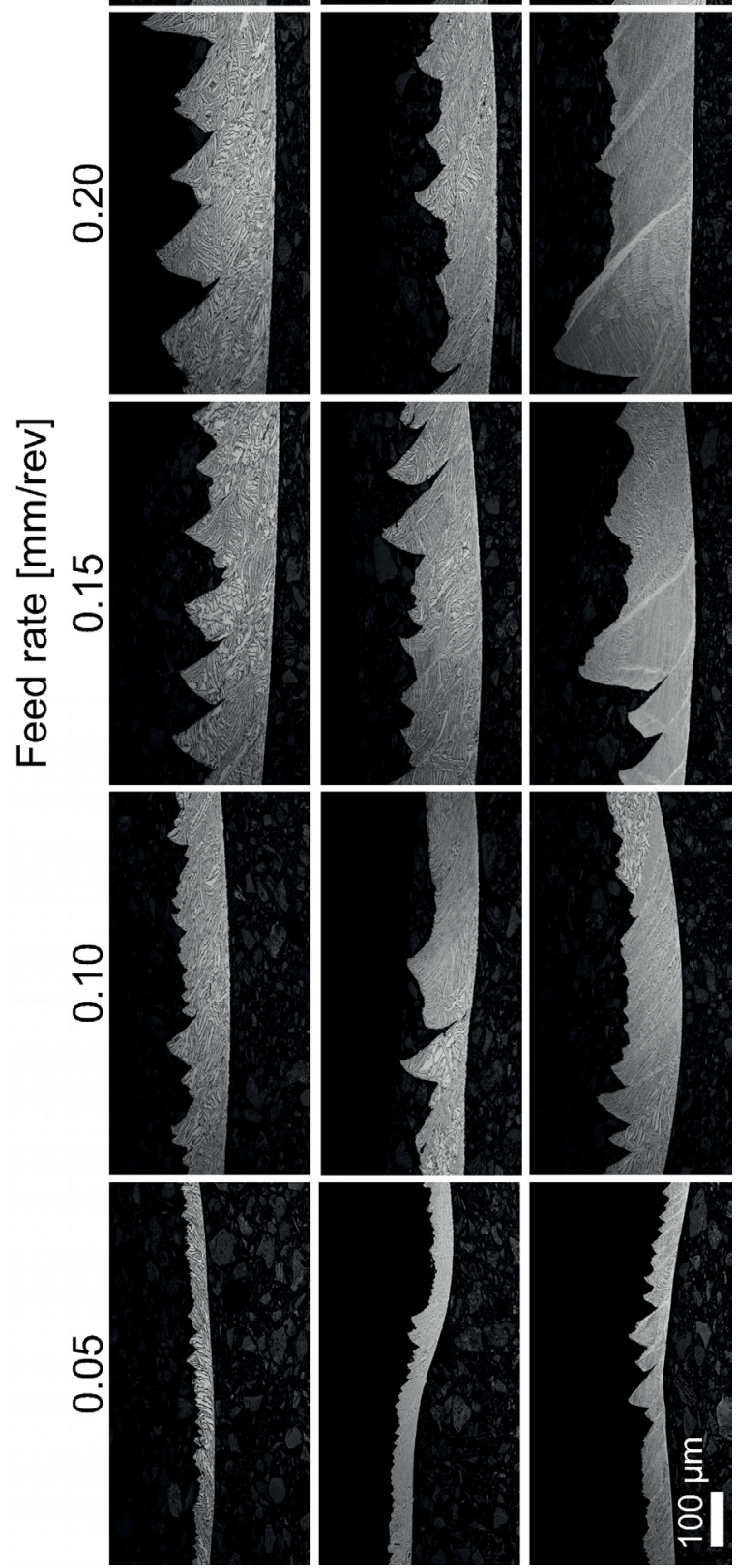

Figure 4. Cross section of chips, magnification is the same for all images.

\section{Chip breakability}

The chip breakability was better for the coarser microstructure, see Figure 5. Thus, it seems as if the anisotropic shear localization behavior at low feed rates aid chip breaking, a benefit of serrated chip formation [9]. 

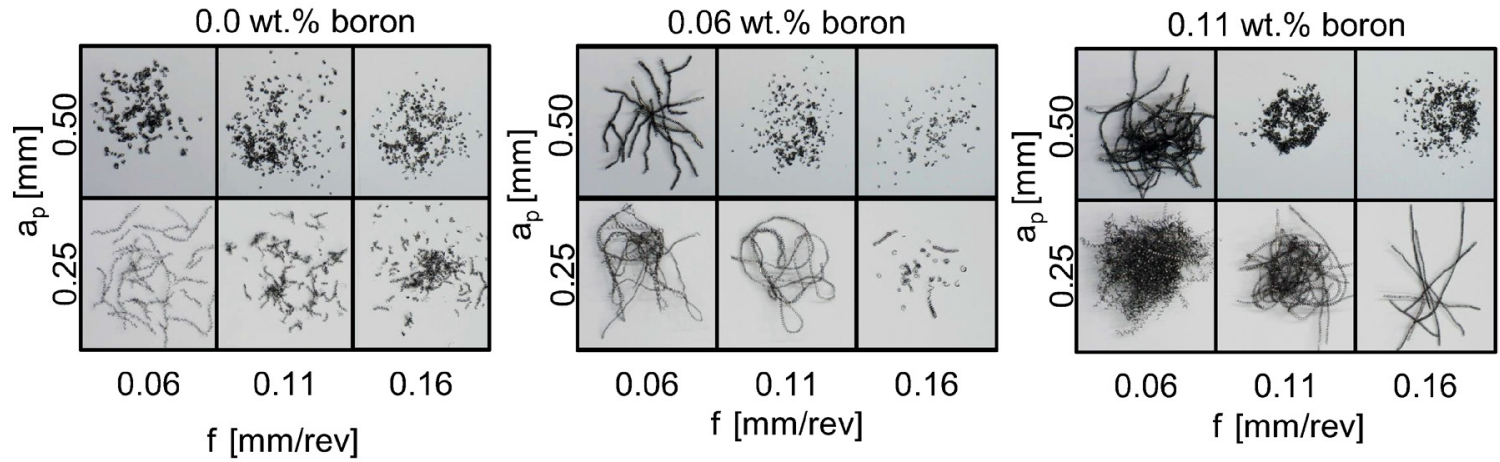

Figure 5. Chip breakability results showing decrease in breakability with increasing boron content.

\section{Cutting forces}

There is little influence on cutting forces between the tested materials, although there is a trend that the boron doped materials have slightly higher feed forces at the lowest feed rate, see Figure 6. That the inhomogeneous deformation show low influence on cutting forces, is in agreement with previous findings [4].

Specific main cutting force

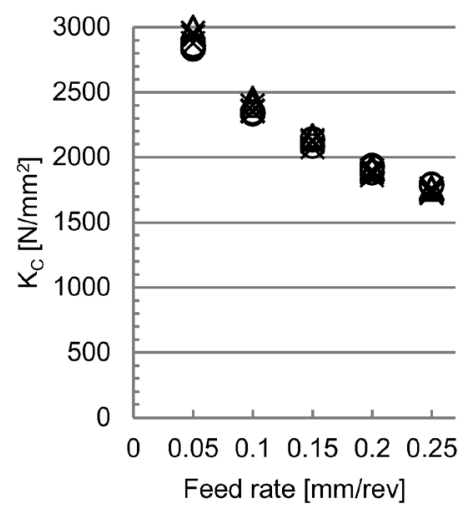

Specific feed cutting force

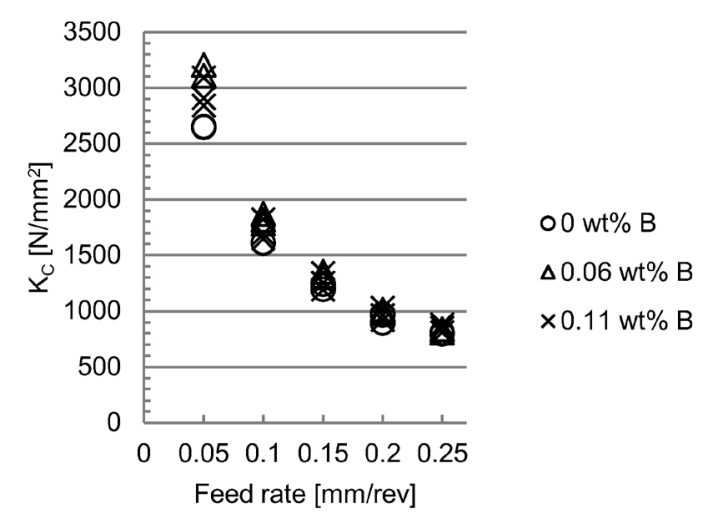

Figure 6. Specific main and feed cutting forces for the three investigated materials machined at $50 \mathrm{~m} / \mathrm{min}$.

\section{Burr formation}

Some anisotropic behavior, i.e. variation of burrs in different colonies, was found in the coarsest microstructure at the lowest feed rates, see Figure 7. Influence of different crystal orientations have been studied previously, in single crystals, and has been shown to affect burr formation [10].
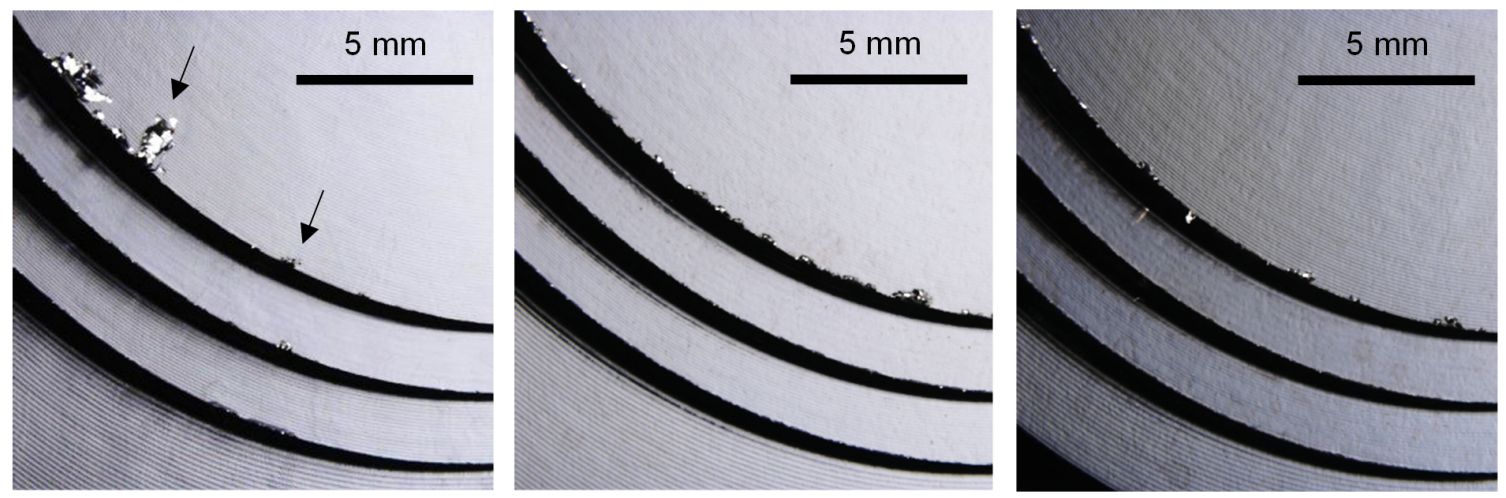
Figure 7. From left to right: $\mathbf{0 , 0 . 0 6}$ and $0.11 \mathrm{wt} \%$ boron. Some anisotropic behavior is observed at the lowest feed rate for the material without boron, where arrows indicates two areas with difference in burr formation. Outer, middle and inner diameters were machined with $0.15,0.10$ and $0.05 \mathrm{~mm} /$ revolution respectively.

\section{Surface roughness}

The material without boron showed a facetted surface finish at most cutting conditions during the experiments. This did however not seem to influence the roughness measurements, see Figure 8. The results showed relatively low influence of the investigated materials, but the material with $0.06 \mathrm{wt} . \%$ boron had the roughest surface finish for the lowest feed rate.

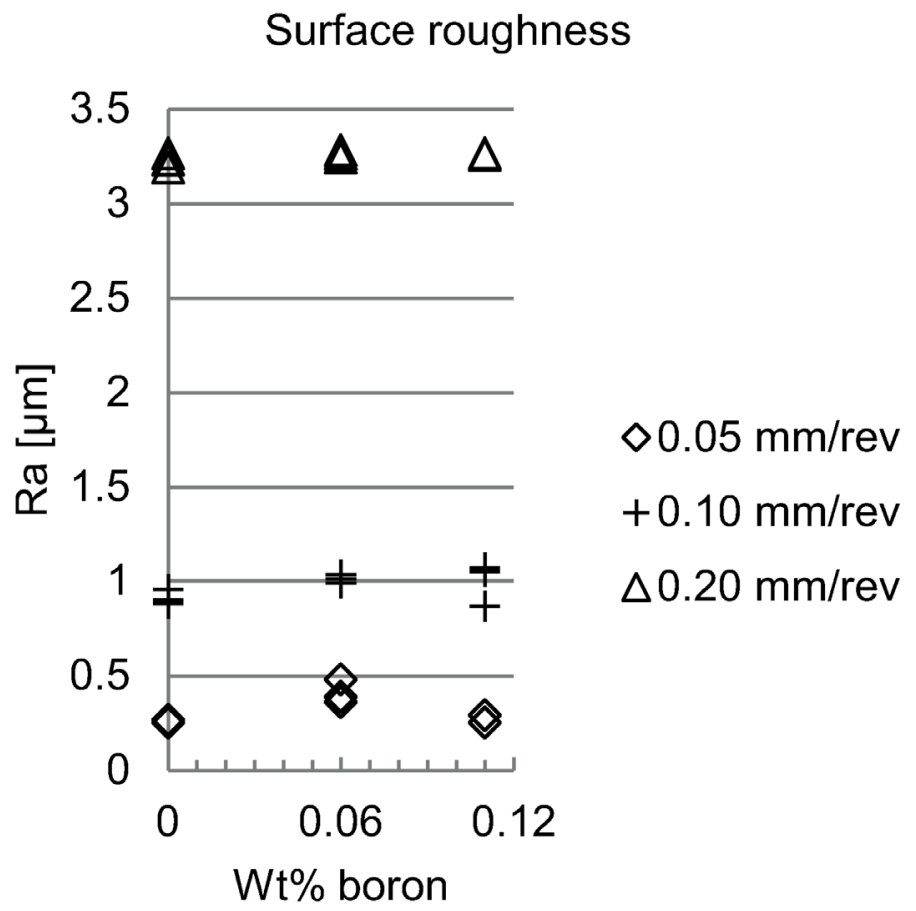

Figure 8. Surface roughness results.

The faceted finish can be seen in Figure 9, where colonies are clearly visible in the coarsest and finest microstructures, respectively. Although variations in surface profiles are larger in the coarse microstructure, the size of the colonies are too big to affect roughness measurements, considering that cut-off length for the high feed rate is $0.8 \mathrm{~mm}$ and $0.25 \mathrm{~mm}$ for the two lower feed rates. Crystal orientation has been found to influence surface roughness in ultra-precision machining [11]. It was suggested that grains should be as small as possible in order to reduce influence of variations because of anisotropic effects. Thus, larger microstructural features produce larger variations in surface topography.

\section{$0.0 w t \% B$}

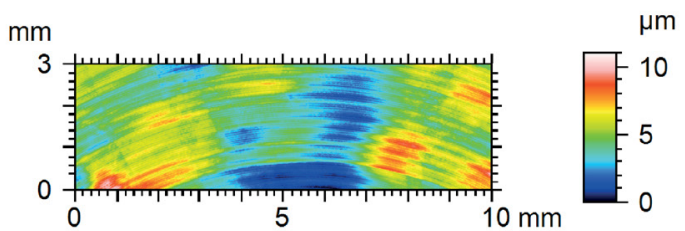

\section{$0.11 w t \%$ B}

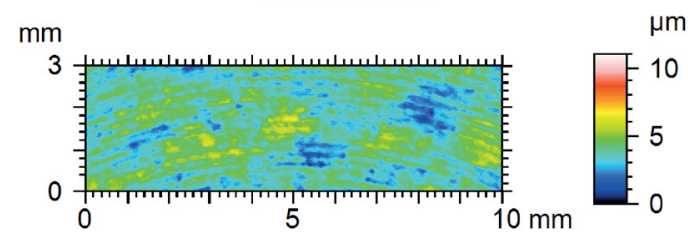

Figure 9. Surface profiles of the finest and coarsest microstructures at a feed rate of $0.05 \mathrm{~mm} / \mathrm{revolution}$.

To further study the influence of cutting parameters compared to work material microstructural effects, surface profiles were investigated before and after filtering. Results for 0.20, 0.10 and $0.05 \mathrm{~mm} /$ revolution in feed rate can be found in Figure 10-12. For 
the unfiltered profiles it is clearly seen that the machining process dominates the surface defects at higher feed rates which also explains the low difference at $0.2 \mathrm{~mm} /$ revolution. At lower feed rates the microstructure seems to dominate the surface profile. However, after filtering, most of the anisotropic surface roughness effects disappear, even for the large "steps" or facets produced by the coarsest microstructure. Some of the roughness is still kept after filtering for the $0.06 \mathrm{wt} . \%$ boron microstructure at the lowest feed rate, see Figure 12. This and the previous differences presented in Figure 8 may still be due to variations or defects in the cutting tool geometry, and should be further investigated. The filtered profiles presented in Figure 10-12 showed relatively low differences in surface roughness, although the unfiltered profiles had completely different appearances.

Unfiltered

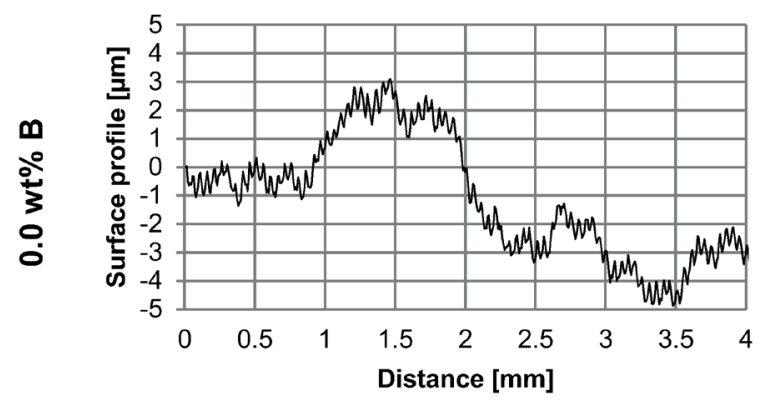

Unfiltered

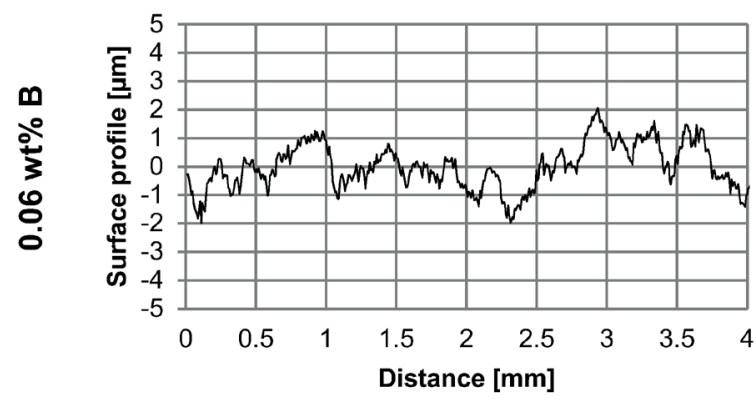

Unfiltered

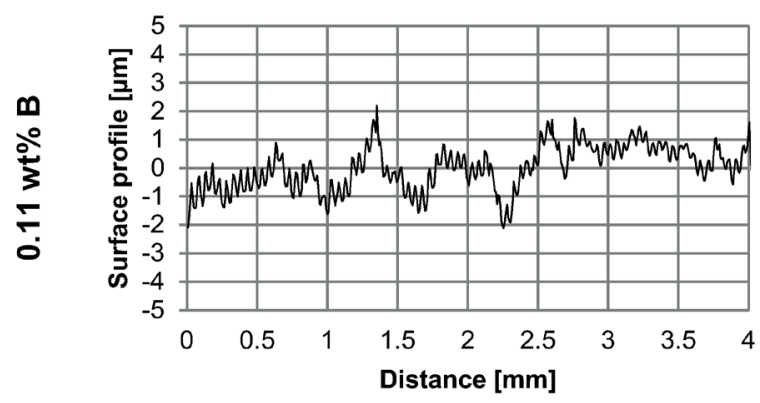

cut-off length $0.25 \mathrm{~mm}$

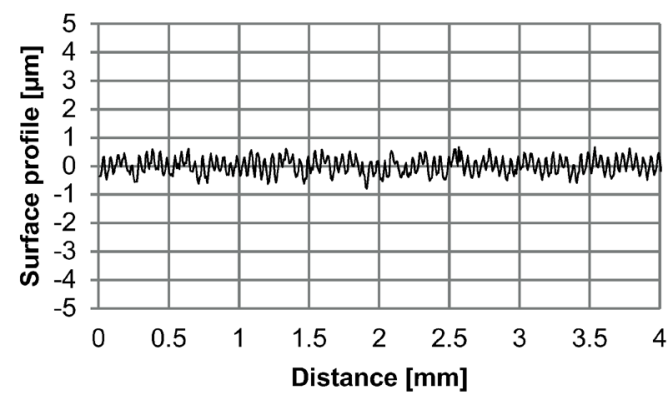

cut-off length $0.25 \mathrm{~mm}$

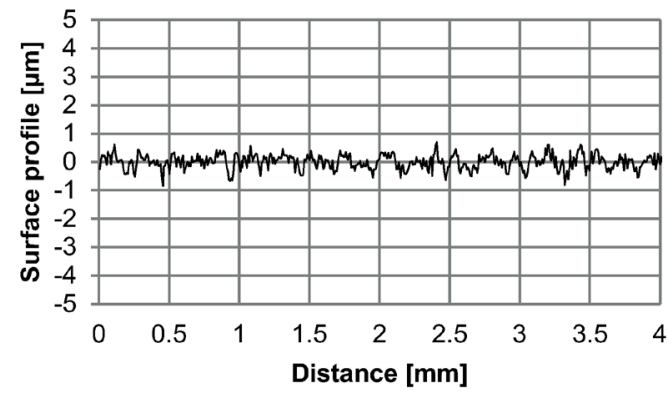

cut-off length $0.25 \mathrm{~mm}$

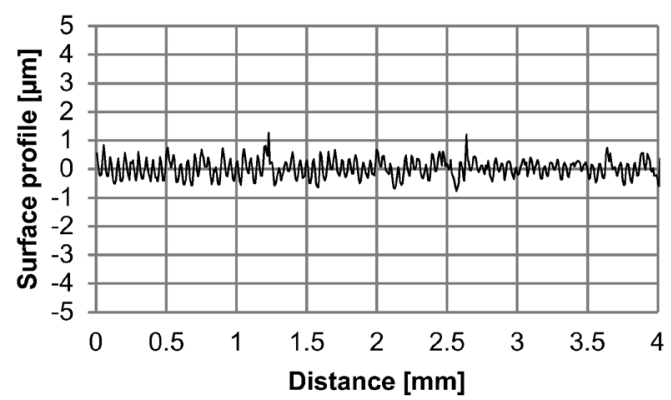

Figure 10. Surface profiles before (left) and after filtering (right) at $0.20 \mathrm{~mm} /$ revolution in feed rate for the three materials. 
Feed rate $=0.10 \mathrm{~mm} / \mathrm{rev}$

Unfiltered

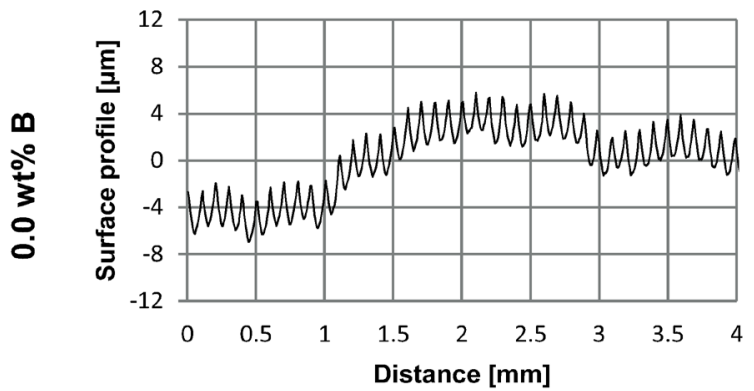

Unfiltered

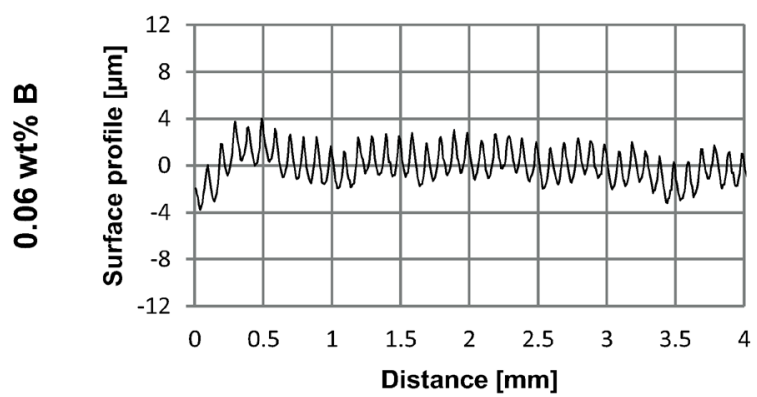

Unfiltered

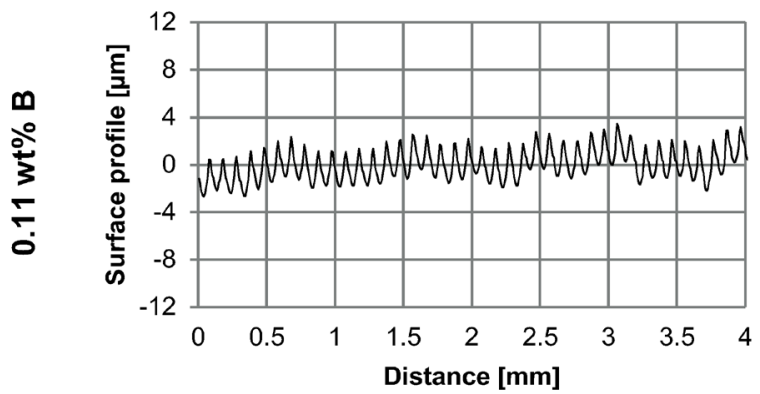

cut-off length $0.25 \mathrm{~mm}$

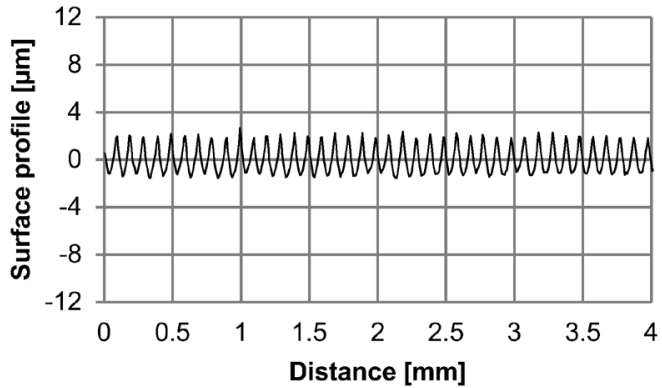

cut-off length $0.25 \mathrm{~mm}$

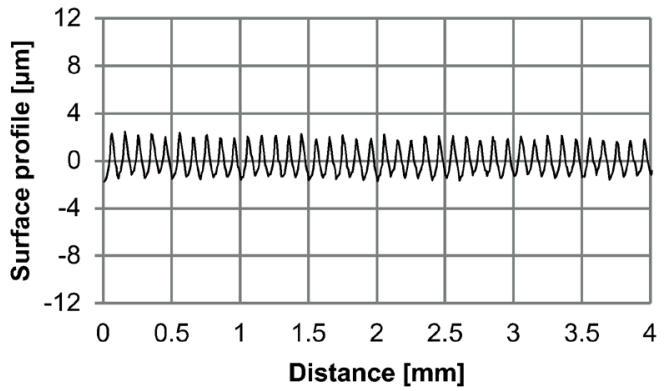

cut-off length $0.25 \mathrm{~mm}$

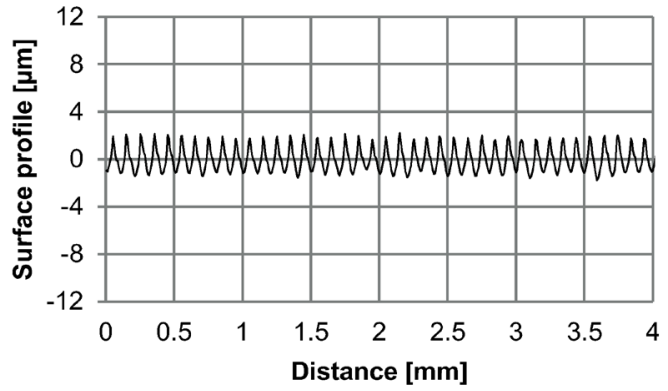

Figure 11. Surface profiles before (left) and after filtering (right) at $0.10 \mathrm{~mm} /$ revolution in feed rate for the three materials. 

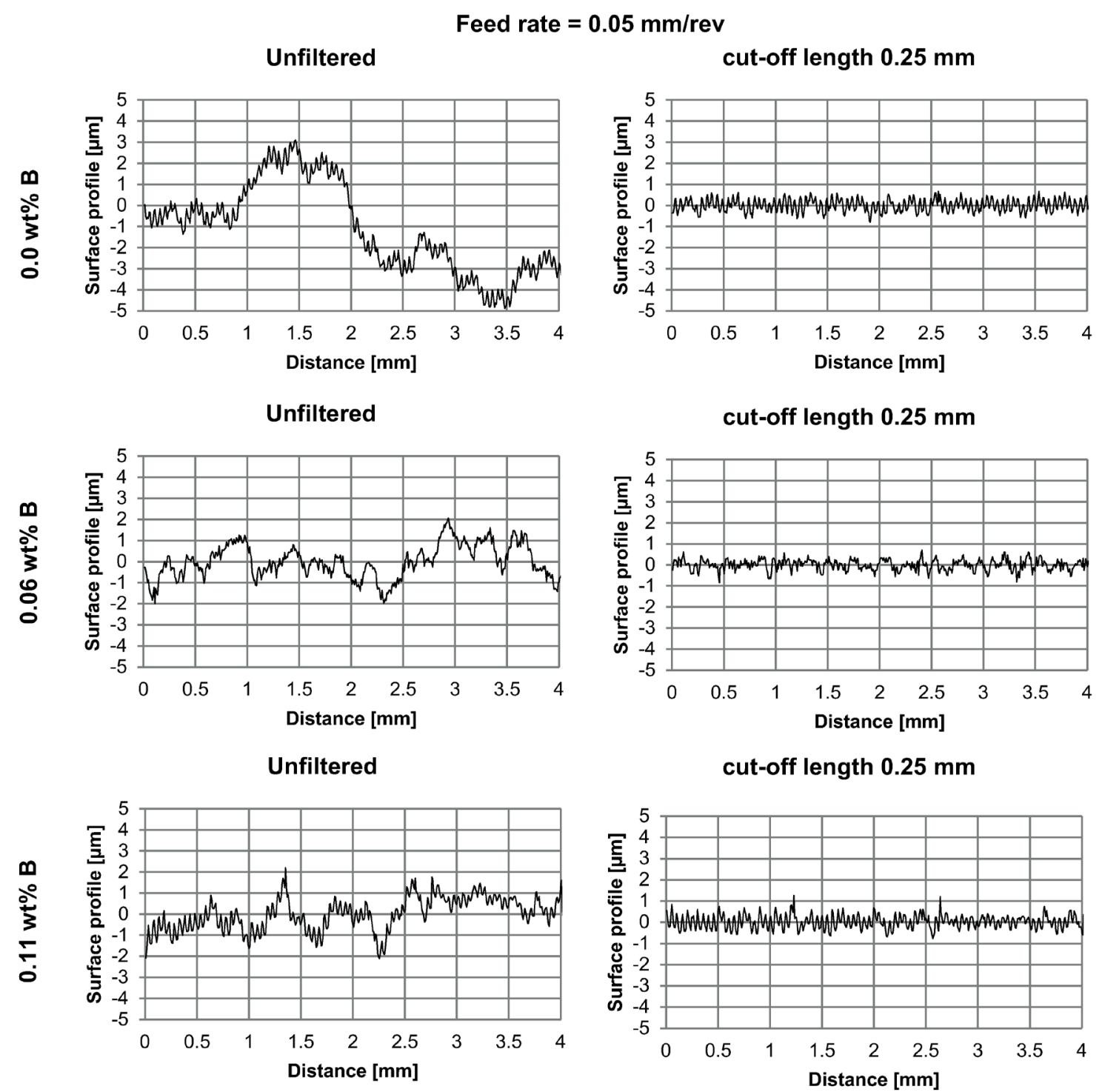

Figure 12. Surface profiles before (left) and after filtering (right) at $0.05 \mathrm{~mm} /$ revolution in feed rate for the three materials.

\section{Tool wear}

The addition of boron had negative impact on flank wear, which can be seen in Figure 13. It does not seem to be any substantial difference between the two boron alloyed materials. 


\section{Flank wear}

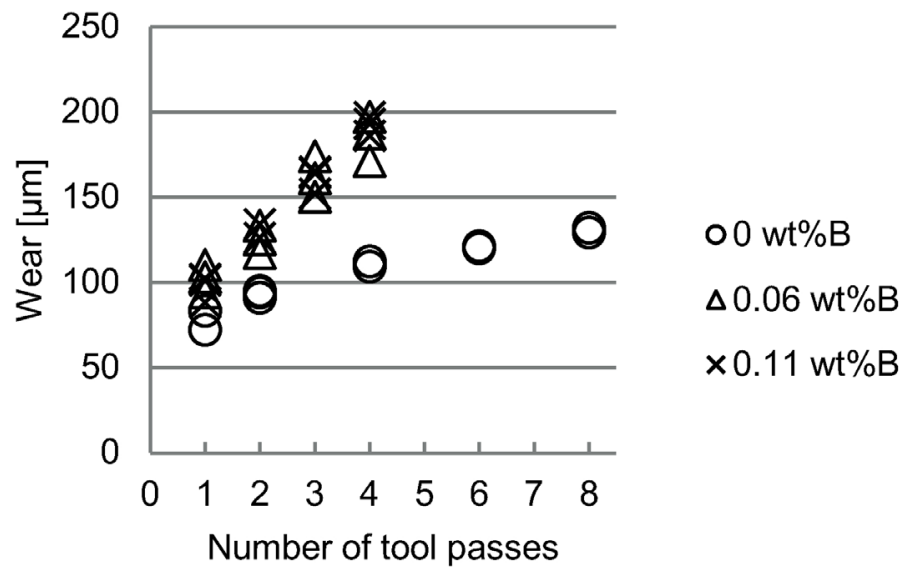

Figure 13. Tool wear results showing the increased tool wear for the two boron containing materials.

When rake face of tools were investigated it was found that the two boron containing materials also had larger crater wear, see Figure 14.
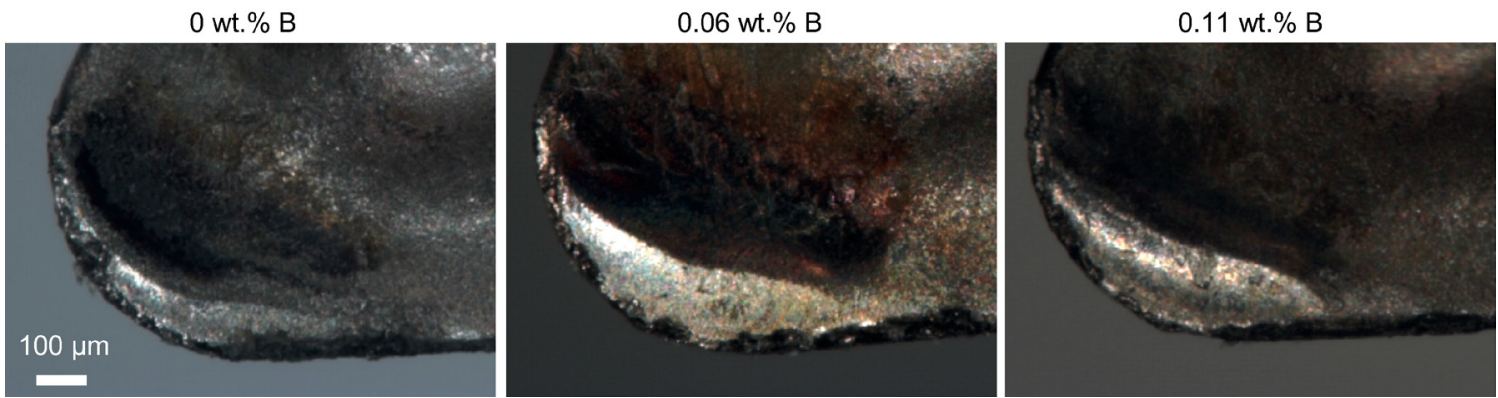

Figure 14. Rake face of inserts after four passes, showing increase in crater wear with increasing boron content.

Both flank and rake face of tools was investigated in higher magnification, both faces showing adhered work material regardless of boron content, see Figure 15 which show rake faces. This layer makes it difficult to tell if the titanium borides give any abrasive wear, but since the amount of particles are twice as many in the material with $0.11 \mathrm{wt} \%$ boron compared to $0.06 \mathrm{wt}$. $\%$, yet they show similar wear, this shouldn't be the main cause of the increased wear. The layers formed on the insert used for boron free material appear rougher and thicker, which may act as effective protection. It should be noted though that the layers seen in Figure 15 are after machining is stopped, and that the situation during the actual cut may be different.
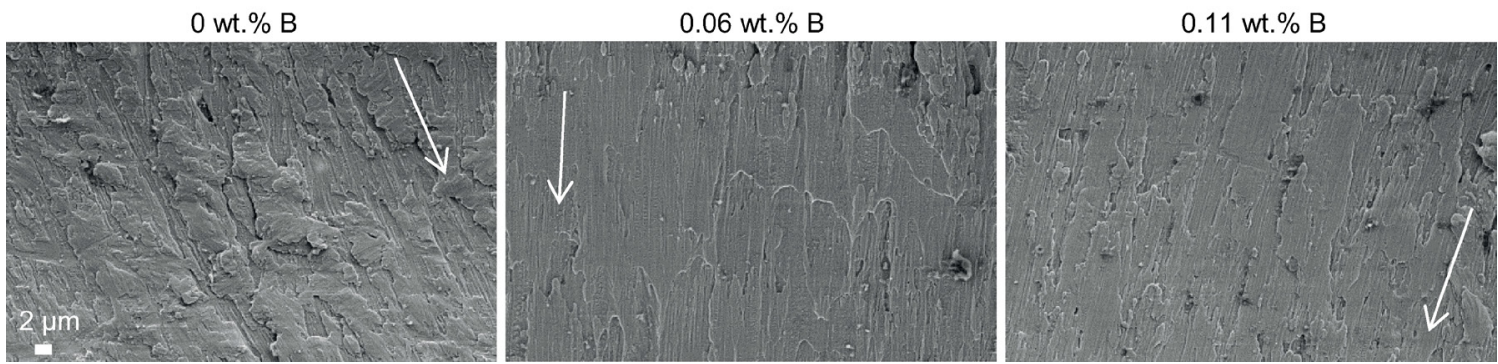

Figure 15. Rake face of tools in higher magnification showing adhered work material for all alloys. Arrows indicate chip flow direction. Magnification is the same for all images.

Another explanation for the wear results may be the differences in shear localization observed in chips. It has been proposed that the localized shear-bands, with corresponding high temperatures leads to high cutting tool temperatures [12]. The large variations in localization found in the coarsest microstructure may therefore distribute more the thermal load on the rake face. 
Cutting forces were measured during tool wear experiments, see Figure 16. Both Cutting forces and feed forces starts at a similar level, which was expected because of that the previous force measurements did not reveal any large differences. After this the forces follow the same trends as the tool wear.
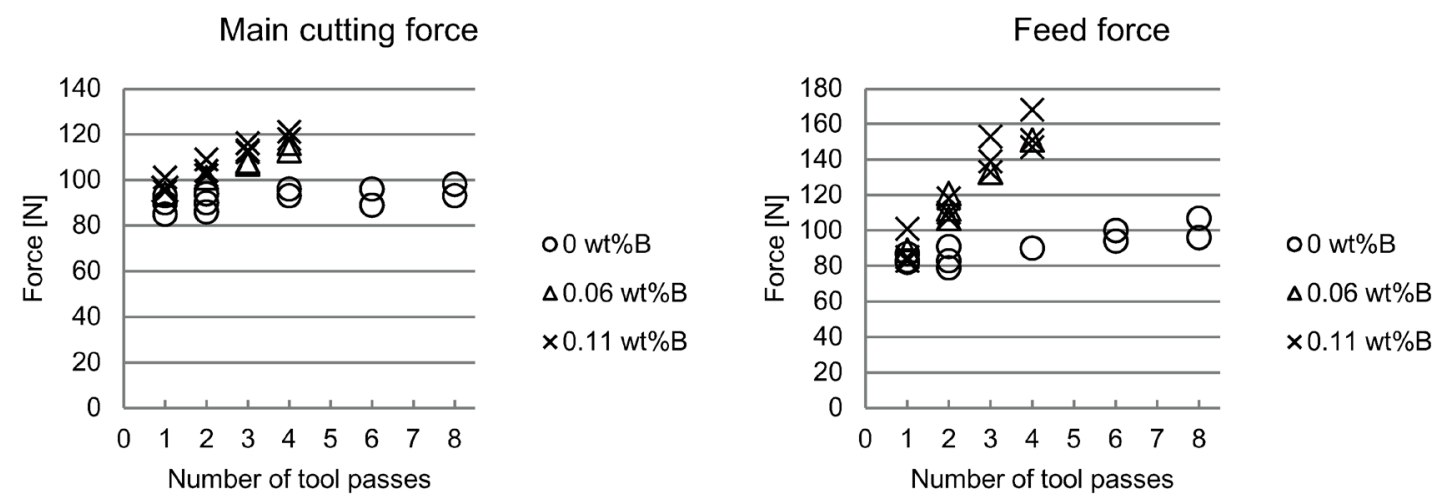

Figure 16. Cutting forces measured during tool wear tests.

\section{Conclusions}

In order to conclude this work it can be said that the additions of boron in cast Ti-6Al-4V influenced machinability in the following ways:

- More isotropic chip formation, with more periodic serrations at higher feed rate.

- Little influence on cutting forces, except on feed force at the lowest feed rate, where $0 \mathrm{wt} . \% \mathrm{~B}$ resulted in slightly lower forces.

- Chip breakability decreased with increasing boron content.

- Surface roughness showed a more complex behavior where $0.06 \mathrm{wt} . \%$ boron resulted in rougher surfaces compared to the other compositions at low feed rate.

- Tool life decreased with increasing boron content.

\section{$\underline{\text { Acknowledgments }}$}

Johan Berglund at Swerea IVF is acknowledged for the help with 3D surface profiles. Göran Sjöberg is acknowledged for valuable input on the manuscript. This work has been supported by the Swedish Agency for Innovation Systems (VINNOVA), which is acknowledged. Support from the Sustainable Production Initiative within the Area of Advance Production at Chalmers University of Technology is acknowledged.

\section{$\underline{\text { References }}$}

[1] S. Tamirisakandala, R. Bhat, J. Tiley and D. Miracle, Scripta Materialia, vol. 53, pp. 1421-1426, 2005.

[2] R. Komanduri and Z. Hou, Metallurgical and Materials Transactions A: Physical Metallurgy and Materials Science, vol. 33, pp. 2995-3010.

[3] M. Armendia, P. Osborne, A. Garay, J. Belloso, S. Turner and P. Arrazola, Materials and Manufacturing Processes, no. 27, pp. 457-461, 2011.

[4] S. Cedergren, G. Petti and G. Sjöberg, Procedia CIRP, vol. 12, pp. 55-60, 2013.

[5] V. Wagner, F. Barelli, G. Dessein, R. Laheurte, P. Darnis, O. Cahuc and M. Mousseigne, Journal of Engineering Manufacture, vol. 233, no. 2, pp. 494-504, 2019.

[6] S. Cedergren, C. Frangoudis, A. Archenti, R. Pederson and G. Sjöberg, International Journal of Advanced Manufacturing Technology, vol. 84, no. 9-12, pp. 2277-2291, 2016.

[7] E. Trent and P. Wright, Metal Cutting 4th ed., Woburn: Butterworth-Heineman, 2000. 
[8] R. Pederson, R. Gaddam and M.-L. Antti, Central European Journal of Engineering, vol. 2, pp. 347-357, 2012.

[9] K. Nakayama, Metal Cutting. Proc. Intern. Conf. on Production Eng., pp. 572-577, 1974.

[10] S. Min, D. Dornfeld, I. Inasaki, H. Ohmori, D. Lee, M. Deichmueller, T. Yasuda and K. Niwa, CIRP Annals - Manufacturing Technology, vol. 55, pp. 103-106, 2006.

[11] Z. Yuan, W. Lee, Y. Yao and M. Zhou, CIRP Annals - Manufacturing Technology, vol. 43, pp. 39-42, 1994.

[12] R. Komanduri and B. V. Turkovich, Wear, vol. 69, pp. 179-188, 1981.

[13] V. Wagner, F. Barelli, G. Dessein, R. Laheurte, P. Darnis, O. Cahuc and M. Moisseigne, Journal of Manufacturing Science and Engineering, vol. 140, pp. 031010-1 - 031010-10, 2018. 